\title{
Self-Efficacy of College Students of Working and Non-Working Mothers
}

\author{
Dr. Indranee Phookan Boorooah*, Kasturi Kotoky** \\ *Professor, Department of Psychology, Gauhati University, Guwahati, Assam, India \\ **Research Scholar, Department of Gauhati University, Guwahati, Assam, India
}

\begin{abstract}
The present study aims to investigate whether the self-efficacy level of college students of working mothers differ significantly from college students of non-working mothers. The study further compared the selfefficacy of college students on the basis of gender. An attempt was made to examine whether there exists any difference between male and female students. The total sample for the study was comprised of 162 students selected randomly from undergraduate level of different colleges of Guwahati, Assam. General Self-Efficacy Scale developed by Jerusalem and Schwarzer was administered to the selected sample to assess their selfefficacy. The obtained data were analyzed by calculating mean, SD and applying t-test. Analysis of the results revealed that students of working mothers had higher self-efficacy compared to the students of non-working mothers. Further findings indicated that there exists no difference in self-efficacy level between male and female college students.
\end{abstract}

Keywords: Self-Efficacy, Working mothers, Non-working mothers, Gender.

\section{INTRODUCTION}

One particular construct that has received considerable interest in the domain of college student adjustment has been self-efficacy or peoples judgments of their capabilities to organize and execute courses of action required to attain designated types of performances. (Bandura, 1986). Research has suggested that selfefficacy is important to not only the academic and social adjustment of students but to their overall wellness and personal adjustment as well (e.g., DeWitz \& Walsh, 2002; Gore, 2006; Solberg \& Villareal, 1997). Selfefficacy has been found to be related to academic achievement, behaviours and attitudes (Faulkner \& Reeves, 2009; Hagger, Chatzisarantis \& Biddle, 2001; Yalcinalp, 2005; Schwarzer \& Fuchs, 2009; Salami, 2004; Salami \& Ogundokun, 2009). It is expected that self-efficacy will be related to students' behaviours and attitudes.Selfefficacy is one of the vital concepts in Albert Bandura's social cognitive theory. According to this theory, human's behavior is not controlled by external and environmental factors; however, cognitive processes have a determining role in the behavior (Pajares, F. 2002). Self-efficacy is based on five cognitive processes symbolizing, forethought, observation, self-regulation and self-reflection. Symbolizing is related to creating a mental image or model in mind. Forethought includes planning on the levels of goals and consequences. Observation links to learn from looking at others behaviour. In self regulation person sets his own goals and standards and later on access his position in relation to his own set standards. Self reflecting processing involves reflection of a person's own past actions and their success and failures. According to Bandura's theory, people with high self-efficacy - that is, those who believe they can perform well-are more likely to view difficult tasks as something to be mastered rather than something to be avoided.Self-efficacy refers to a person's belief in his/her ability to organise and execute a required course of action to achieve a desired result (Bandura, 1997). Self-efficacy determines an individual's resiliency to adversity and his/her vulnerability to stress and depression (Bandura, Caprara, Barbaranelli, Gerbino \& Pastorelli, 2003). General self-efficacy aims at a broad and stable sense of personal competence to deal effectively with a variety of stressful situations (Adeyemo, 2008; Schwarzer, 1994). Perhaps for an individual who has low happiness and life satisfaction and high depression, having high self-efficacy will help him/her in displaying appropriate behaviours and positive attitudes as regards his/her academic work. In recent years the study of self-efficacy has received increasing attention in the educational field, not only from the teachers' point of view, but also from the perspective of students. Research suggests that student self-efficacy is an antecedent of motivation and also the future performance of students (Bores-Rangel, Church, Szendre, \& Reeves, 1990; Elias, \& Loomis, 2004; Pintrich \& Schunk, 1995; Multon, Brown, \& Lent, 1991; Zimmerman, 2000). This finding is congruent with the Social Cognitive Theory (SCT; Bandura, 1986, 1997, 2001), which postulates that the beliefs that people have about themselves are key elements in the exercise of control and personal agency, and in which individuals are viewed both as products and producers of their own environments (Pajares, 1996). 
Self-efficacy is defined as "People's judgements of their capabilities to organize and execute courses of action required to attain designated types of performances" (Bandura, 1986). Self- efficacy means one's belief in his ability to complete tasks in specific situations. It influences emotional, behavioural, and thought patterns in different human levels. Self-efficacy or belief-related ability is one of the most powerful characteristics associated with an individual's motivation, health, flexibility, and capabilities to face difficulties of life (Bandura, 2001). A person with high self-efficacy is less concerned with failures and he is stronger in confronting difficulties (Lee, L., Arthur, A., \& Avis, M. 2008). It is important for young youths to have increased belief in their capacity to control one's environment or self-efficacy since this would pave the way for carrying out task with confidence and belief in oneself which would tend to lead to improved psychological wellbeing.Today women from all corners have started working in various organizations and the entry of women in the workforce has brought changes in the structure and function of families. Every member of the family occupies a vital position in the interaction map of the child but among them the role of mother is important and varied. A mother is particularly important not because she has special skills but because she is with her children for a much greater time than any other person and her instructions reflects a very strong influence on attitudes, abilities and behaviour of children. Most of those children who are successful and well-adjusted come from homes where parental attitudes are favorable and a wholesome relationship existed between children and parents (Priyanka Aeri and Devina Jain 2010). Mother plays important role in the personality development of the children by shaping their intellectual and social behaviour. Therefore, effort has been made to study whether there exists any difference in the results among students having working or non-working mothers. Researchers have identified gender differences in a variety of fields such as mental health, cognitive abilities and personality. So an attempt has been made to examine whether there exists any difference between male and female students. Thus the present study aims to determine whether the self-efficacy level of college students of working mothers differ significantly from college students of non-working mothers. The study further examined whether there exists any difference in self-efficacy level between male and female students. The study was conducted among the college students of Guwahati city. Although number of related research have been done or are ongoing around the world, little is known about the youth of Guwahati which is the premier city of North-East India in South-East Asia.

\section{SIGNIFICANCE OF THE STUDY}

Research has suggested that human beings can excel at any point in life and live a healthy life by emphasizing and enhancing positive resources or capacities. Positive elements may play an important role among students too. Students are viewed as leaders of tomorrow. They have academic success as their major goal and need good mental health to be able to succeed in their academic pursuit. One particular construct that has received considerable interest in the domain of college student adjustment has been self-efficacy or people's judgments of their capabilities to organize and execute courses of action required to attain designated types of performances. (Bandura, 1986). Research has suggested that self-efficacy is important to not only the academic and social adjustment of students but to their overall wellness and personal adjustment as well (e.g., DeWitz \& Walsh, 2002; Gore, 2006; Solberg \& Villareal, 1997). Thus, the main aim of the study is to determine the selfefficacy among college students. Further, in the present scenario women employment rate has increased very rapidly over the last several years. Today women from all corners have started working in various organizations and the entry of women in the workforce has brought changes in the structure and function of families. Every member of the family occupies a vital position in the interaction map of the child but among them the role of mother is important and varied. Mother plays important role in the personality development of children by shaping their intellectual and social behaviour. Therefore, effort has been made to study whether there exists any difference in self-efficacy among students having working or non-working mothers. Researchers have also identified gender differences in a variety of fields such as mental health, cognitive abilities and personality. So an attempt has also been made to examine whether there exists any difference between male and female students.

\section{OBJECTIVES}

- To find out the level of Self-efficacy of students based on the working and non-working status of mothers.

- To find out the level of Self-efficacy of male and female students.

\section{HYPOTHESIS}

- HO: There will be no difference in self-efficacy level of first year college students based on working and nonworking status of mother.

- H0: There will be no difference in self-efficacy level of male and female first year college students. 
V.

SAMPLE

The field of the proposed study is Guwahati, Assam. The total sample for the study was comprised of 162 students selected randomly from undergraduate courses of different colleges of Guwahati and the sampling procedure adopted was random sampling.

Sample Distribution

\begin{tabular}{|l|l|l|l|}
\hline \multirow{2}{*}{ Gender } & Working Status of Mothers & \multirow{2}{*}{ Total } \\
\cline { 2 - 4 } & Working & Non-Working & 77 \\
\hline Male & 27 & 50 & 85 \\
\hline Total & 35 & 50 & N=162 \\
\hline
\end{tabular}

VI. RESEARCH TOOL

General Self-Efficacy Scale (GSE):

The GSE is a 10-item scale designed to assess optimistic self-beliefs used to cope with a variety of demands in life. The scale was designed to assess self-efficacy, i.e., the belief that one's actions are responsible for successful outcomes. The scaled score for each question ranges from 1 to 4 . Higher scores indicate stronger patient's belief in self-efficacy. The scale was originally developed by Jerusalem and Schwarzer in 1981 in Germany and has been translated into many languages. Studies have shown that the GSE has high reliability, stability, and construct validity (Leganger, Kraft, Roysamb, 2000; Schwarzer, Mueller, \& Greenglass 1999). Cronbach alpha ranges from 0.75 to 0.94 across a number of different language versions (Rimm and Jerusalem 1999; Luszczynska, Scholz, Schwarzer, 2005).

\section{VII.}

STATISTICAL APPLICATION

The data collected was analysed by using the statistical methods. Descriptive statistics like Mean and Standard Deviation; and inferential statistics like ' $t$ ' test was used.

\section{PROCEDURE FOR DATA COLLECTION}

The population of the study included college students of Guwahati city, Assam. Since this survey is conducted in reputed government colleges of Guwahati, so permission was taken from the principal of the concerned college. The actual survey was conducted during the respondent's break time in order not to disturb their daily routine and studies. The participants of the study were identified through randomized group design and their consent for participation in the study was taken and no one was forced to participate in the study. It was conveyed to the participants that they will be given a psychological questionnaire which needs to be filled up by them and that the activities undertaken were for research purpose. The participants were told that they could withdraw from the study at any time without any obligation, even after giving consent, if they wished so. Confidentiality of information was ensured. The students were fully assured that their responses would be kept confidential and would be used only for research purpose. At the same time they were made to understand the importance of their honesty in responding to the questionnaire.In order to conduct this study, initially the researcher established a rapport with the participants. Then the questionnaires were distributed personally to the participants and requisite directions and instructions were given. In general it consumes maximum 10 minutes to complete the questionnaire. The questionnaires were then collected there and then. The students were thanked for their kind cooperation. The completed questionnaires were later analyzed by applying required statistics.

\section{RESULT AND DISCUSSION}

The result of the present study is shown in the following tables:

Table1: Mean, SD and 't' values of college students based on working and non-working status of mother for self-efficacy.

\begin{tabular}{|l|l|l|l|l|l|l|l|}
\hline Variable & $\begin{array}{l}\text { Working Status of } \\
\text { Mother }\end{array}$ & $\mathbf{N}$ & Mean & SD & T & df & $\begin{array}{l}\text { Sig (2- } \\
\text { tailed) }\end{array}$ \\
\hline $\begin{array}{l}\text { Self- } \\
\text { Efficacy }\end{array}$ & Working & 62 & 29.97 & 3.387 & 2.289 & 160 & .023 \\
\cline { 2 - 5 } & Non-Working & 100 & 28.55 & 4.081 & & & \\
\hline
\end{tabular}

From table1, it can be inferred that in terms of self-efficacy level, the ' $t$ ' value was found to be significant at $\mathrm{P}<0.05$. Hence the first hypothesis is rejected and we can say that there exists difference in self 
efficacy level of college students based on working and non-working status of mother. The Mean score was also found to be higher among the students whose mother is working than the students whose mother is nonworking. Thus, we can conclude that students of working mother have belief in their capacity to have control over the environment and cope effectively with stressful situations than the students of non-working mother. Students of working mothers are given more opportunities to be independent and look after their daily activities and needs.

Table2: Mean, SD and ' $t$ ' values of male and female college students for self-efficacy.

\begin{tabular}{|l|l|l|l|l|l|l|l|}
\hline Variable & Gender & $\mathbf{N}$ & Mean & SD & T & df & $\begin{array}{l}\text { Sig (2- } \\
\text { tailed) }\end{array}$ \\
\hline \multirow{2}{*}{$\begin{array}{l}\text { Self- } \\
\text { Efficacy }\end{array}$} & Male & 77 & 29.45 & 3.796 & 1.131 & 160 & .260 \\
\cline { 2 - 9 } & Female & 85 & 28.76 & 3.951 & & & \\
\hline
\end{tabular}

Significant level is at $\mathrm{P}<0.05$

Supportive data from table 2 shows that the probable ' $t$ ' values at $0.05 \%$ level of significance in terms of self efficacy were not found to be significant for the male and female students. Therefore the second hypothesis can be accepted; and thus we can say that there exists no difference in self efficacy level among male and female college students.

\section{CONCLUSION}

The findings clearly indicated that maternal employment had positive impact on self-efficacy of the college students. Students of working mothers had higher self-efficacy compared to the students of non-working mothers. Saini (2005) conducted a study on family environment and academic achievement of children of working and non-working mothers. Major findings of the study (Saini, 2005) revealed that children of working mothers were more independent than children of non-working mothers and children of working mothers were higher in academic score than those of the children of non-working mothers. Thus, on the basis of the result and previous research, we can conclude that a mother who successfully manages both an outside job and parenthood provides a role model for her child. Children can get inspired to pursue their dreams and ambition. Mothers who effectively manage work and family can instil good work ethic into their kids. They encourage their kids to take responsibility. With both parents working, each family member has to play a more active role. Working mothers have to move out of the house leaving all the household chores intact, the children behind understand their responsibilities and manages to do all their tasks without being dependent on others and thus become smart and active enough. They tend to look after one another and help in other ways. Children learn skills that they would not learn otherwise. Raising independent children prepares them for the real world and inculcates in them sense of responsibility. They become more confident and believe that they can perform well and deal effectively with variety of situations in life.Results of the present study also revealed that there is no significant difference in self-efficacy level of male and female college students. Reviews of previous studies, related to the topic also support this finding. Shikullaku(2013) has done a study on "The Relationship between Self - efficacy and Academic Performance in the Context of Gender among Albanian Students" and found that there is no significant difference in the level of self-efficacy between male and female. In additions, Elmotaleb and Saha (2013) revealed in their study that self-efficacy have negative significant co-relationship with sexes. But, it is also seen from previous research that the result of current study is not found to be consistent with the findings of Tenaw (2013), when he reported that there is significant difference in the self-efficacy between sexes. In addition, McKenzie (1999) also found similar finding when he investigated that there is positive co-relationship between gender and level of self-efficacy. The findings of the present study reflect only a trend in this limited sample and thus further research should be carried out with larger group of participants. In addition, it is also recommended that more variable (such as socio-economic status, races, academic achievement etc) should be taken into consideration in order to determine the level of self-efficacy. Moreover, this study is using quantitative method to find out the result. It is recommended that in-depth investigation can be made by using both quantitative and qualitative method to collect data information. Moreover, similar and related topic of research is recommended to do more in the future. The findings of the study need to be corroborated and expanded in future studies which should be a prospective study and which draws samples from the college setup as there is a scarcity of such studies in the districts as well as the whole state of Assam.

\section{REFERENCE:}

[1] Anuradha,S. (1999). Women and Work: Human Resource Management Perspective. New Delhi: Pyan Publishing House.

[2] ASL Sowmya, Dr. E. Manjuvani(2011), A Comparative Study on Achievement Motivation of Children of Employed and Non-Employed Mothers. 
[3] Bandura, A. (2001), Social Cognitive Theory: An agentic perspective. Annual review of Psychology, 52. $1-26.4$.

[4] Goswami (2000), Achievement Motivation and Anxiety among the children of working and non-working mothers in secondary schools of Shillong.

[5] Greene, B. A. \& DeBacker, T. K. (2004). Gender and orientations toward the future: Links to motivation. Educational Psychology Review, 16 (2), p. 91-120.

[6] Linnenbrink, E. A. \& Pintrich, P. R. (2002). Motivation as an enabler for academic success. School Psychology Review, 31, p. 313-327.

[7] Priyanka Aeri and Devina Jain (2010). Effect of Employment Status of Mothers on Conceptual Skills of Preschoolers, Department of Human Development, Guru Nanak Girls College, Yamuna Nagar, Haryana, India () Kamla-Raj 2010 J Soc Sci, 24(3): 213-215 (2010).

[8] Saini, S. (2005). Family Environment and Academic Achievement of Adolescent Children of Working and Non-Working Mothers. Indian Educational Review,41(2),87-95

[9] Schwarzer, R. (Ed.). (1992). Self efficacy: Thought control of action. Washington, DC: Hemisphereigfield, A., \& Eccles, J. S. (2002). Development of achievement motivation. San Diego, CA: Academic Press. 